\title{
Association between hemoglobin glycation index and cardiometabolic risk factors in Korean pediatric nondiabetic population
}

\author{
Bora Lee, MD', \\ You Jung Heo, MD', \\ Young Ah Lee, MD, PhD', \\ Jieun Lee, MD², \\ Jae Hyun Kim, MD', \\ Seong Yong Lee, $\mathrm{MD}, \mathrm{PhD}^{4}$, \\ Choong Ho Shin, MD, PhD', \\ Sei Won Yang, MD, PhD'
}

'Department of Pediatrics, Seoul National University Children's Hospital, Seoul National University College of Medicine, Seoul, ${ }^{2}$ Department of Pediatrics, Inje University Ilsan Paik Hospital, Goyang, 'ㄹepartment of Pediatrics, Seoul National University Bundang Hospital, Seongnam, ${ }^{4}$ Department of Pediatrics, Seoul Metropolitan Government-Seoul National University Boramae Medical Center, Seoul, Korea
Purpose: The hemoglobin glycation index ( $\mathrm{HGl}$ ) represents the degree of nonenzymatic glycation and has been positively associated with cardiometabolic risk factors (CMRFs) and cardiovascular disease in adults. This study aimed to investigate the association between $\mathrm{HGl}$, components of metabolic syndrome (MS), and alanine aminotransferase (ALT) in a pediatric nondiabetic population.

Methods: Data from 3,885 subjects aged 10-18 years from the Korea National Health and Nutrition Examination Survey (2011-2016) were included. HGI was defined as subtraction of predicted glycated hemoglobin $\left(\mathrm{HbA} 1_{c}\right)$ from measured $\mathrm{HbA}_{1} 1_{c}$. Participants were divided into 3 groups according to $\mathrm{HGl}$ tertile. Components of MS (abdominal obesity, fasting glucose, triglycerides, high-density lipoprotein cholesterol, and blood pressure), and proportion of MS, CMRF clustering ( $\geq 2$ of MS components), and elevated ALT were compared among the groups.

Results: Body mass index (BMI) z-score, obesity, total cholesterol, ALT, abdominal obesity, elevated triglycerides, and CMRF clustering showed increasing HGI trends from lower-to-higher tertiles. Multiple logistic regression analysis showed the upper HGI tertile was associated with elevated triglycerides (odds ratio, 1.65; 95\% confidence interval, 1.18-2.30). Multiple linear regression analysis showed HGI level was significantly associated with BMI $z$-score, $\mathrm{HbA}_{c}$, triglycerides, and ALT. When stratified by sex, age group, and BMI category, overweight/obese subjects showed linear HGI trends for presence of CMRF clustering and ALT elevation.

Conclusion: $\mathrm{HGl}$ was associated with CMRFs in a Korean pediatric population. High $\mathrm{HGI}$ might be an independent risk factor for CMRF clustering and ALT elevation in overweight/obese youth. Further studies are required to establish the clinical relevance of $\mathrm{HGl}$ for cardiometabolic health in youth.

Keywords: Glycated hemoglobin, Hemoglobin glycation index, Risk factor, Alanine aminotransferase, Metabolic syndrome, Hepatic steatosis

\section{Introduction}

Prevalence of obesity and type 2 diabetes mellitus (T2DM) in the pediatric population has increased worldwide. ${ }^{1,2}$ The same phenomena have been observed in Korean children and adolescents. ${ }^{3,4)}$ Comorbidities of obesity and complications of T2DM have become important issues in the pediatric population. ${ }^{5,6}$ Therefore, prevention of pediatric obesity and T2DM is critical for reducing the burden of these health problems. ${ }^{1,7)}$ For the earlier intervention, there have been studies conducted for developing and evaluating the markers for these cardiometabolic risk factors (CMRFs) associated with obesity and T2DM. ${ }^{8,9)}$

Glycated hemoglobin $\left(\mathrm{HbAl}_{\mathrm{c}}\right)$ is an index that reflects the mean blood glucose for the prior $2-3$ months and is a gold standard for controlling blood glucose among patients with diabetes
Address for correspondence: Jae Hyun Kim, MD

Department of Pediatrics, Seoul National University Bundang Hospital, Seongnam 13620, Korea

Tel: +82-31-787-7287

Fax: +82-31-787-4054

E-mail: pedendo@snubh.org

https://orcid.org/0000-0002-02037443 
mellitus (DM). ${ }^{10,11)}$ However, some studies have reported differences in $\mathrm{HbAl}_{\mathrm{c}}$ in patients with similar mean blood glucose levels. ${ }^{12,13)}$ Approximately $60 \%-80 \%$ of the $\mathrm{HbAl}_{\mathrm{c}}$ variance could be explained by mean blood glucose levels, while the rest is influenced by ethnic and genetic factors, ${ }^{14,15)}$ glucose metabolism, and biological factors involved in hemoglobin glycation. ${ }^{16)}$ A statistical method to quantify the difference between predicted and actual $\mathrm{HbA} 1_{\mathrm{c}}$ levels was provided by Hempe et al., ${ }^{17)}$ which was termed hemoglobin glycation index (HGI). HGI is defined as the value obtained by subtracting predicted $\mathrm{HbAl}_{\mathrm{c}}$ from measured $\mathrm{HbAl}_{\mathrm{c}}$. Predicted $\mathrm{HbAl}_{\mathrm{c}}$ is calculated by using equations from linear regression of $\mathrm{HbAl}_{c}$ and fasting blood glucose. When HGI is high or low, it means that the measured $\mathrm{HbA} 1_{c}$ is higher or lower than the predicted $\mathrm{HbAl}_{\mathrm{c}}$ at the blood glucose level. HGI indicates the degree of nonenzymatic glycation of hemoglobin, which has been positively correlated with complications of DM. ${ }^{18,19)}$ Moreover, a recent study revealed that HGI is associated with hepatic steatosis in adults without DM, and is considered an emerging risk factor for metabolic syndrome (MS) and future T2DM. ${ }^{20)}$

However, to date, only one study has been reported about HGI in children with type 1 diabetes mellitus (T1DM), which showed HGI as a robust measure of $\mathrm{HbA} 1_{c}$ bias. ${ }^{21)}$ Further, no studies have been performed on the association between HGI and CMRFs in the pediatric population without DM. Therefore, the aim of this study was to describe the distribution of HGI and to investigate the correlation of HGI with MS, its components, and alanine aminotransferase (ALT) as an index of nonalcoholic fatty liver disease (NAFLD) in a pediatric nondiabetic population.

\section{Materials and methods}

\section{Study subjects}

This study was based on data from the Korea National Health and Nutrition Examination Survey (KNHANES) 2011-2016. This cross-sectional nationwide survey, conducted by the Korea Centers for Disease Control and Prevention (KCDC), used a multistage, stratified, and clustered probability sampling method to select a representative sample of the Korean civilian population. Of the total 47,164 participants, children and adolescents aged between 10 and 18 years were selected $(n=5,043)$. Exclusion criteria were as follows: subjects who fasted less than 8 hours before blood sampling $(n=553)$; absence of results of fasting glucose or elevated fasting glucose values of $\geq 126 \mathrm{mg} / \mathrm{dL}(\mathrm{n}=1,050)$; absence of results of $\mathrm{HbA} 1_{\mathrm{c}}$ or elevated $H b A 1_{c}$ of $\geq 6.5 \%(n=1,074)$; previously diagnosed DM $(n=3)$; pregnancy $(n=0)$; absence of any component of MS $(n=1,105)$, and absence of anthropometric measurements $(n=382)$. Finally, 3,885 participants (2,074 young males and 1,811 young females) were eligible for the analysis (Fig. 1).

\section{Anthropometric and laboratory data}

Anthropometric measurements were performed on all participants by trained personnel. Height was measured to the nearest $0.1 \mathrm{~cm}$ by using a stadiometer (Seca 225, Seca, Hamburg, Germany). Weight was measured by using an electronic balance (GL-600020, G-tech, Seoul, Korea) to the nearest $0.1 \mathrm{~kg}$, and body mass index (BMI) was calculated as weight $(\mathrm{kg})$ divided by height squared $\left(\mathrm{m}^{2}\right)$. Height and BMI were transformed into $z$-scores by using the 2017 Korean National Growth Charts. ${ }^{22)}$ Waist circumference (WC) was measured to the nearest $0.1 \mathrm{~cm}$ by using a flexible tape measure, from the midpoint between the lowest border of the rib cage and the uppermost border of the iliac crest at the end of expiration (Seca 220, Seca). Blood pressure (BP) was measured by using a mercury sphygmomanometer (Baumanometer Desk model 0320 in 2011-2012 and Baumanometer Wall Unit 33[0850] in 2013-2016, Baum, NY, USA) on the right arm after the subject had rested for at least 5 minutes in a seated position. BP was measured 3 times, and the mean of the last 2 values were used for the analyses.

Fasting blood samples were collected from each participant by trained medical personnel. Plasma glucose, total cholesterol, high-density lipoprotein cholesterol (HDL-C), triglyceride (TG), aspartate aminotransferase, and ALT were measured by using a Hitachi Automatic Analyzer 7600 (Hitachi, Tokyo, Japan). The level of $\mathrm{HbAl}_{\mathrm{c}}$ was measured by using high performance liquid chromatography (HLC-723G7, Tosoh, Tokyo, Japan), which was the certified method by the National Glycohemoglobin Standardization Program. All laboratory tests were performed in the Central Laboratory.

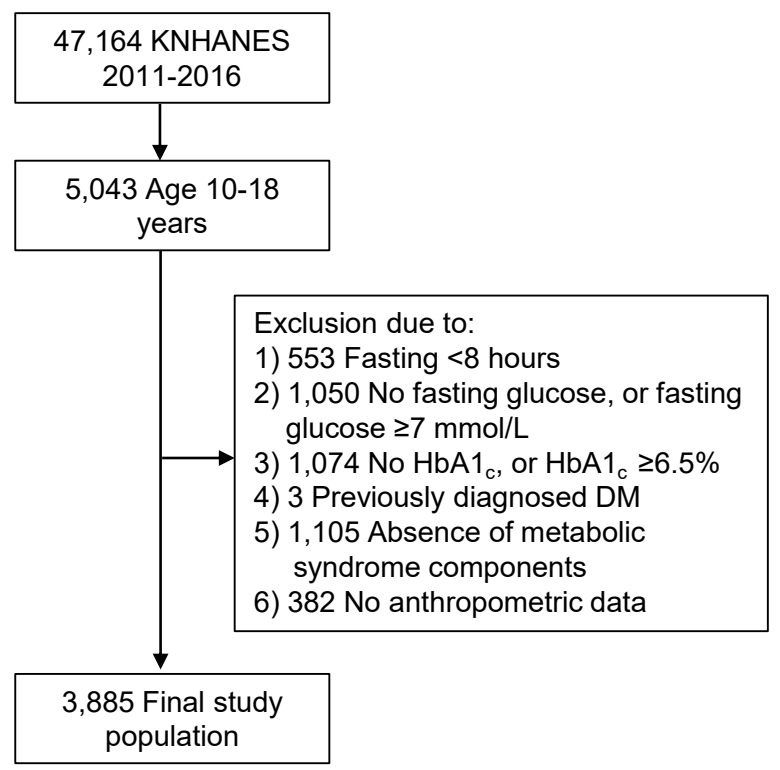

Fig. 1. Flow chart of eligible study population. KNHANES, the Korea National Health and Nutrition Examination Survey; $\mathrm{HbA1}_{C}$, glycated hemoglobin; DM, diabetes mellitus. 


\section{Definition of $\mathrm{HGl}$ and MS}

HGI was defined as the difference between measured $\mathrm{HbAl}{ }_{c}$ and predicted $\mathrm{HbA} 1_{\mathrm{c}}\left(\mathrm{HGI}=\right.$ measured $\mathrm{HbA} 1_{c}$-predicted $\mathrm{HbAl}_{c}$ ). Predicted $\mathrm{HbA} 1_{c}$ was calculated by using the following formula through individual measurements of fasting plasma glucose (FPG), which were derived from linear regression analysis of measured $\mathrm{HbAl}_{\mathrm{c}}$ and fasting glucose $\left(\mathrm{HbA} 1_{c}\right.$ $(\%)=0.0089 \times \mathrm{FPG}[\mathrm{mg} / \mathrm{dL}]+4.6173[\mathrm{R}$-squared $=0.0466, P$ $<0.001]$ ) (Fig. 2). Study subjects were classified into 3 groups according to the tertile of HGI.

MS was defined by using the International Diabetes Federation criteria. ${ }^{23)}$ MS was confirmed, when a subject had abdominal obesity with 2 or more abnormalities in the following 4 measurements: TG, HDL-C, BP, and FPG. Abdominal obesity was defined when WC was $\geq 90$ th percentile in those aged 10-15 years or WC was $\geq 90 \mathrm{~cm}$ in males and $\geq 85 \mathrm{~cm}$ in females aged 16-18 years. Abnormal results were defined as follows: systolic or diastolic $\mathrm{BP} \geq 130 / 85 \mathrm{mmHg}, \mathrm{FPG} \geq 100 \mathrm{mg} / \mathrm{dL}, \mathrm{TG} \geq 150 \mathrm{mg} /$ $\mathrm{dL}, \mathrm{HDL}-\mathrm{C}<40 \mathrm{mg} / \mathrm{dL}$ in males aged $10-18$ years and females aged $10-15$ years, and $<50 \mathrm{mg} / \mathrm{dL}$ in females aged between 16 and 18 years. CMRF clustering was defined as the presence of $\geq 2$ abnormal components of MS. ${ }^{8,24}$ ALT was used as a marker for NAFLD in a pediatric population. ${ }^{25)}$ ALT elevation was defined as $\geq 30 \mathrm{IU} / \mathrm{L}$ for males and $\geq 19 \mathrm{IU} / \mathrm{L}$ for females. ${ }^{26,27)}$

\section{Statistical analysis}

Data were analyzed using Stata 14.2 (StataCorp LP, College Station, TX, USA) with svy commands appropriate for the KNHANES sampling design. Data were expressed as the means \pm standard error for continuous variables or number of subjects (weighted percent) for categorical variables. Linear regression analysis was used to calculate predicted HGI values. Clinical characteristics were compared between tertiles of HGI by using the Student $t$-test or regression analysis for continuous

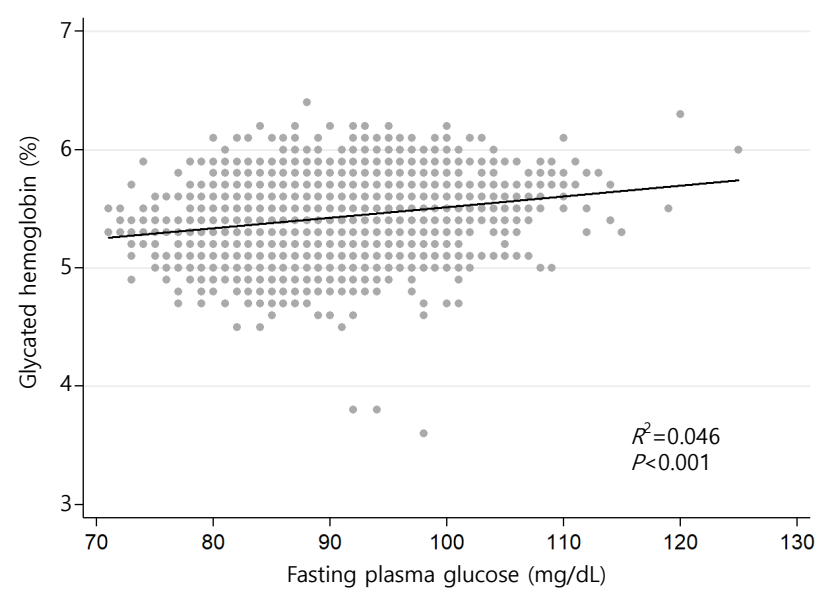

Fig. 2. Association between glycated hemoglobin and fasting plasma glucose among eligible participants. variables, or logistic regression analysis and chi-square test for categorical variables. $P$-value for comparison between tertiles and $P$ for trend from the lower to the upper HGI tertiles were obtained. Multiple logistic regression analysis was performed to determine the odds ratio (OR) with $95 \%$ confidence interval (CI) for association between HGI and components of MS and elevated ALT with adjustment for hemoglobin and BMI z-score. Further multiple logistic regression analyses were performed to identify association between HGI and CMRF clustering, MS and ALT elevation, after stratification by sex, age group (10-14 years and 15-18 years) and BMI category (normal weight and overweight/obese). Association between HGI and CMRFs were analyzed using simple and multiple linear regression analysis adjusting hemoglobin and BMI $z$-score. Due to the multicollinearity, $\mathrm{HbAl}_{\mathrm{c}}$ and $\mathrm{HGI}$ was not used in the same analysis. A $P$ value of $<0.05$ was considered statistically significant.

\section{Ethics statement}

The KNHANES was approved by the Institutional Review Board of the KCDC (2011-02CON-06-C, 2012-01EXP-01-2C, 2013-07CON-03-4C, 2013-12EXP-03-5C). Written informed consent was obtained from all participants prior to the survey. The present study was approved by the Institutional Review Board of the Seoul National University Bundang Hospital (approval number: X-1807/483-902).

\section{Results}

\section{Clinical characteristics of study participants by HGl tertiles}

The mean of HGI (\%) was $0.000 \pm 0.006$, with a range of between -1.887 and 1.002. The mean and range of HGI by lower (HGI-T1), mid (HGI-T2), and upper (HGI-T3) tertiles were $-0.277 \pm 0.006$ ( -1.887 to -0.107$), 0.000 \pm 0.005$ ( -0.105 to 0.111 ),

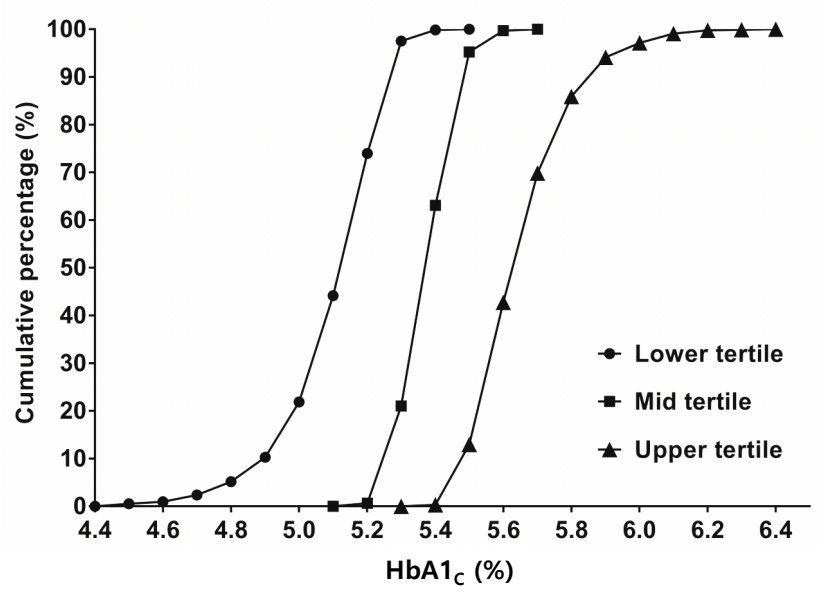

Fig. 3. Cumulative proportion of glycated hemoglobin $\left(\mathrm{HbA}_{\mathrm{c}}\right)$ by tertiles of hemoglobin glycation index. 
and $0.280 \pm 0.005$ (0.113 to 1.002$)$, respectively. The cumulative proportion of $\mathrm{HGI}$ according to measured $\mathrm{HbAl}_{\mathrm{c}}$ is presented in Fig. 3.

The anthropometric and metabolic characteristics of study participants according to tertiles of HGI values are shown in Table 1 . The mean age was $14.3 \pm 0.1$ years, and $53.6 \%$ of participants were males. Overweight or obese subjects were $19.9 \%(\mathrm{n}=768)$. Participants were divided into 2 age groups; $10-14$ years $(\mathrm{n}=2,253,48.8 \%)$ and $15-18$ years $(\mathrm{n}=1,632,51.2 \%)$. No significant differences between the groups were observed for age, sex, height $z$-scores, and WC. BMI $z$-scores and proportion of obesity increased with respect to HGI tertile. Subjects in higher HGI tertiles had higher values of $\mathrm{HbA} 1_{\mathfrak{c}}$, without differences in FPG. Serum level of total cholesterol and ALT statistically significantly increased with increasing HGI (Table
1). Proportion of abdominal obesity, elevated TG, and CMRF clustering showed an increasing tendency with respect to HGI tertile (Fig. 4). However, proportion of MS, hyperglycemia, high BP, low HDL-C, and elevated ALT did not reveal differences among the groups (Fig. 4).

\section{Association between HGl and components of MS}

There was no significant difference in components of MS and elevated ALT between HGI-T1 and HGI-T2 (Table 2). However, adjusted OR (95\% CI) of elevated TG in HGI-T3 as compared with that in HGI-T1 was $1.65(1.18-2.30)$. Other components, including MS and elevated ALT, did not show statistical significance.

In linear regression analysis, $\mathrm{BMI} z$-score, $\mathrm{HbAl}_{c}, \mathrm{TG}$, and

Table 1. Clinical characteristics of study participants

\begin{tabular}{|c|c|c|c|c|c|c|}
\hline Characteristic & Total & HGI-T1 & HGI-T2 & HGI-T3 & $P$-value & $P$ for trend \\
\hline No. of participants & $3,885(100)$ & $1,247(34.1)$ & $1,280(32.7)$ & 1,358 (33.3) & & \\
\hline HGI (\%) & & & & & $<0.001$ & $<0.001$ \\
\hline Mean \pm SE & $0.000 \pm 0.006$ & $-0.277 \pm 0.005$ & $0.004 \pm 0.002^{* *}$ & $0.280 \pm 0.005^{* *}$ & & \\
\hline Range & -1.887 to 1.002 & -1.887 to -0.107 & -0.105 to 0.111 & 0.113 to 1.002 & & \\
\hline Age (yr) & $14.3 \pm 0.1$ & $14.4 \pm 0.1$ & $14.3 \pm 0.1$ & $14.3 \pm 0.1$ & 0.468 & 0.309 \\
\hline Sex, boys & $2,074(53.6)$ & $645(51.8)$ & $706(55.5)$ & $723(53.4)$ & 0.269 & 0.488 \\
\hline Height z-score & $0.20 \pm 0.02$ & $0.13 \pm 0.04$ & $0.25 \pm 0.04$ & $0.22 \pm 0.04$ & 0.064 & 0.066 \\
\hline BMI z-score & $0.00 \pm 0.02$ & $-0.05 \pm 0.04$ & $-0.04 \pm 0.04$ & $0.09 \pm 0.05$ & 0.060 & 0.030 \\
\hline Waist circumference (cm) & $70.3 \pm 0.2$ & $70.2 \pm 0.3$ & $70.1 \pm 0.3$ & $70.6 \pm 0.4$ & 0.503 & 0.330 \\
\hline BMI category & & & & & 0.034 & 0.003 \\
\hline Obesity & $403(10.9)$ & $108(8.8)$ & $127(10.5)$ & $168(13.2)$ & & \\
\hline Overweight & $365(9.0)$ & $115(9.8)$ & $116(8.5)$ & $134(8.9)$ & & \\
\hline Normal & $3,117(80.1)$ & $1,024(81.4)$ & $1,037(81.0)$ & $1,056(77.9)$ & & \\
\hline Systolic BP (mmHg) & $107.9 \pm 0.2$ & $108.3 \pm 0.3$ & $107.7 \pm 0.3$ & $107.7 \pm 0.3$ & 0.316 & 0.203 \\
\hline Diastolic BP (mmHg) & $66.3 \pm 0.2$ & $66.4 \pm 0.3$ & $66.0 \pm 0.3$ & $66.2 \pm 0.4$ & 0.565 & 0.443 \\
\hline Fasting glucose (mg/dL) & $90.2 \pm 0.1$ & $90.3 \pm 0.2$ & $90.1 \pm 0.2$ & $90.3 \pm 0.2$ & 0.613 & 0.936 \\
\hline $\mathrm{HbA}_{\mathrm{c}}(\%)$ & $5.418 \pm 0.006$ & $5.141 \pm 0.006$ & $5.420 \pm 0.003^{* *}$ & $5.689 \pm 0.005^{* *}$ & $<0.001$ & $<0.001$ \\
\hline Hemoglobin $(\mathrm{g} / \mathrm{L})$ & $14.12 \pm 0.03$ & $14.23 \pm 0.04$ & $14.17 \pm 0.04$ & $13.94 \pm 0.05$ & 0.244 & $<0.001$ \\
\hline Total cholesterol (mg/dL) & $157.0 \pm 0.5$ & $155.0 \pm 0.9$ & $156.9 \pm 0.9$ & $159.1 \pm 0.9^{* *}$ & 0.006 & 0.001 \\
\hline Triglyceride (mg/dL) & $73.9 \pm 0.8$ & $72.9 \pm 1.2$ & $73.9 \pm 1.2$ & $75.1 \pm 1.4$ & 0.449 & 0.207 \\
\hline $\mathrm{HDL}-\mathrm{C}(\mathrm{mg} / \mathrm{dL})$ & $50.8 \pm 0.2$ & $50.6 \pm 0.3$ & $50.7 \pm 0.4$ & $51.0 \pm 0.4$ & 0.770 & 0.474 \\
\hline AST (IU/L) & $18.9 \pm 0.2$ & $18.6 \pm 0.2$ & $19.1 \pm 0.4$ & $19.1 \pm 0.2$ & 0.217 & 0.131 \\
\hline $\operatorname{ALT}(I U / L)$ & $15.2 \pm 0.3$ & $14.2 \pm 0.3$ & $15.7 \pm 0.7^{*}$ & $15.7 \pm 0.5^{*}$ & 0.016 & 0.015 \\
\hline Elevated ALT & $280(8.5)$ & $80(6.4)$ & $90(7.1)$ & $110(8.5)$ & 0.189 & 0.082 \\
\hline Abdominal obesity & $383(10.7)$ & $106(9.1)$ & $127(10.4)$ & $150(12.6)$ & 0.059 & 0.022 \\
\hline Hyperglycemia & $312(8.0)$ & $103(8.5)$ & $102(7.5)$ & $107(7.9)$ & 0.699 & 0.600 \\
\hline High blood pressure & $126(3.5)$ & $39(3.1)$ & $40(3.5)$ & $47(3.9)$ & 0.681 & 0.378 \\
\hline Elevated triglyceride & $295(8.1)$ & $73(6.3)$ & $95(7.8)$ & $127(10.2)$ & 0.005 & 0.001 \\
\hline Low HDL-C & $578(15.8)$ & $196(16.7)$ & $180(15.1)$ & $202(15.6)$ & 0.656 & 0.545 \\
\hline Cardiometabolic risk factor clustering & $346(9.5)$ & $99(8.4)$ & $108(8.8)$ & $139(11.4)$ & 0.046 & 0.027 \\
\hline Metabolic syndrome & $72(2.2)$ & $21(1.8)$ & $16(1.7)$ & $35(3.0)$ & 0.120 & 0.098 \\
\hline
\end{tabular}

Values are presented as number (weighted percent) or mean \pm standard error.

P-value was calculated for comparison between HGI-T1 and HGI-T2/T3 $\left({ }^{*} P<0.05,{ }^{* *} P<0.01\right)$.

$P$ for trend was calculated using linear trend from HGI-T1 to HGI-T3.

HGl, hemoglobin glycation index; HGI-T1, lower tertile of HGl; HGI-T2, mid tertile of HGl; HGI-T3, upper tertile of HGl; BMI, body mass index; BP, blood pressure; HbA1 , glycated hemoglobin; HDL-C, high-density lipoprotein cholesterol; AST aspartate aminotransferase; ALT, alanine aminotransferase. 
ALT showed a significant positive association with HGI after adjusting BMI z-score and hemoglobin (Table 3). WC, BP, FPG, and HDL-C were not associated with HGI.

When stratified according to sex, age group, and BMI category, those overweight and obese showed increased OR for predicting CMRF clustering and ALT elevation with respect to the HGI (Table 4). OR (95\% CI) for predicting CMRF clustering and ALT elevation in overweight/obese participants was 2.92 (1.47-5.80) and 2.72 (1.24-5.98), respectively. However, HGI was not significant for predicting MS.

\section{Discussion}

In this cross-sectional study of Korean adolescents, HGI was associated with CMRFs. BMI $z$-score, $\mathrm{HbAl}_{c}, \mathrm{TG}$, and ALT levels showed linear correlation with HGI. Moreover, elevated TG was independently associated with HGI levels after adjusting for BMI $z$-score and hemoglobin. In overweight/ obese subjects, HGI was associated with CMRF clustering and elevated ALT.

People with consistently higher or lower $\mathrm{HbA} 1_{c}$ values
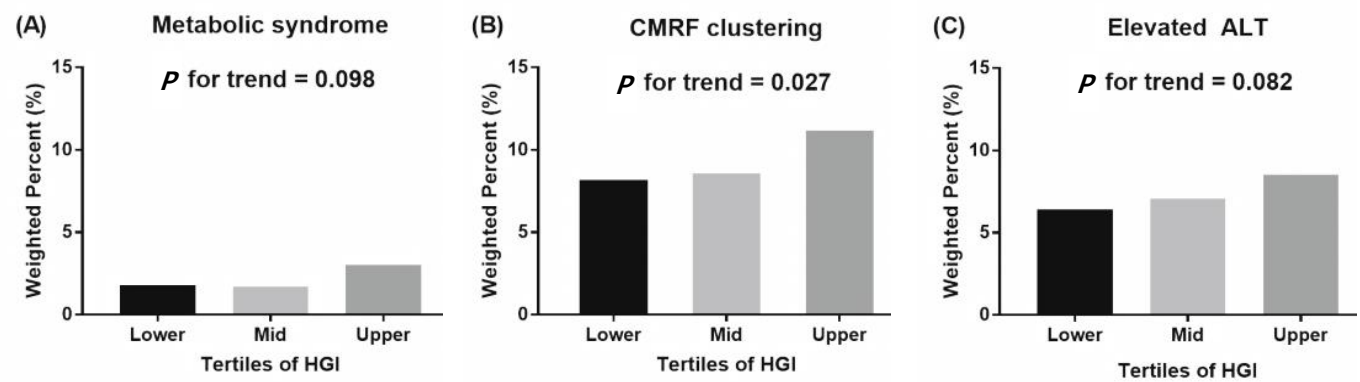

Fig. 4. Proportions of metabolic syndrome (A), cardiometabolic risk factor (CMRF) clustering (B), and elevated alanine aminotransferase (ALT) (C) by hemoglobin glycation index (HGI) tertiles.

Table 2. Association between HGI tertiles and cardiometabolic risk factors

\begin{tabular}{|c|c|c|c|c|}
\hline \multirow{2}{*}{ Variable } & \multicolumn{2}{|c|}{ HGI-T1 vs. HGI-T2 } & \multicolumn{2}{|c|}{ HGI-T1 vs. HGI-T3 } \\
\hline & OR $(95 \% \mathrm{Cl})$ & $P$-value & OR $(95 \% \mathrm{Cl})$ & $P$-value \\
\hline \multicolumn{5}{|c|}{ Abdominal obesity } \\
\hline Univariate & $1.16(0.86-1.57)$ & 0.325 & $1.43(1.05-1.95)$ & 0.022 \\
\hline Multivariate & $1.04(0.64-1.71)$ & 0.873 & $1.45(1.07-1.97)$ & 0.488 \\
\hline \multicolumn{5}{|l|}{ Hypertension } \\
\hline Univariate & $1.12(0.68-1.84)$ & 0.660 & $1.25(0.76-2.04)$ & 0.377 \\
\hline Multivariate ${ }^{*}$ & $1.17(0.69-1.97)$ & 0.554 & $1.33(0.79-2.26)$ & 0.286 \\
\hline \multicolumn{5}{|c|}{ Elevated plasma glucose } \\
\hline Univariate & $0.87(0.63-1.21)$ & 0.411 & $0.92(0.66-1.28)$ & 0.603 \\
\hline Multivariate ${ }^{*}$ & $0.87(0.62-1.21)$ & 0.399 & $0.89(0.64-1.24)$ & 0.494 \\
\hline \multicolumn{5}{|c|}{ Elevated triglyceride } \\
\hline Univariate & $1.26(0.89-1.78)$ & 0.187 & $1.71(1.23-2.36)$ & 0.001 \\
\hline Multivariate $^{*}$ & $1.26(0.88-1.80)$ & 0.208 & $1.65(1.18-2.30)$ & 0.003 \\
\hline \multicolumn{5}{|c|}{ Decreased HDL-C } \\
\hline Univariate & $0.89(0.70-1.14)$ & 0.360 & $0.92(0.72-1.19)$ & 0.548 \\
\hline Multivariate $^{*}$ & $0.86(0.67 .1 .11)$ & 0.258 & $0.80(0.62-1.04)$ & 0.092 \\
\hline \multicolumn{5}{|c|}{ CMRF clustering } \\
\hline Univariate & $1.05(0.77-1.43)$ & 0.756 & $1.41(1.04-1.90)$ & 0.027 \\
\hline Multivariate ${ }^{*}$ & $0.98(0.69-1.39)$ & 0.899 & $1.15(0.83-1.61)$ & 0.386 \\
\hline \multicolumn{5}{|c|}{ Metabolic syndrome } \\
\hline Univariate & $0.92(0.44-1.96)$ & 0.837 & $1.68(0.91-3.11)$ & 0.097 \\
\hline Multivariate $^{*}$ & $0.77(0.31-1.96)$ & 0.589 & $1.09(0.51-1.96)$ & 0.832 \\
\hline \multicolumn{5}{|l|}{ Elevated ALT } \\
\hline Univariate & $1.12(0.80-1.58)$ & 0.502 & $1.34(0.96-1.95)$ & 0.081 \\
\hline Multivariate ${ }^{*}$ & $1.18(0.75-1.57)$ & 0.657 & $1.18(0.80-1.74)$ & 0.393 \\
\hline
\end{tabular}

$\mathrm{HGl}$, hemoglobin glycation index; $\mathrm{HGl}-\mathrm{T} 1$, lower tertile of $\mathrm{HGl}$; $\mathrm{HGl}-\mathrm{T} 2$, mid tertile of $\mathrm{HGl}$; $\mathrm{HGl}-\mathrm{T} 3$, upper tertile of $\mathrm{HGl}$; OR, odds ratio; $\mathrm{Cl}$, confidence interval; HDL-C, high-density lipoprotein cholesterol; CMRF, cardiometabolic risk factor; ALT, alanine aminotransferase.

*Adjusted for body mass index z-score and hemoglobin. 
Table 3. Association between HGI and cardiometabolic risk factors

\begin{tabular}{|c|c|c|c|c|}
\hline \multirow{2}{*}{$\mathrm{HGl}$} & \multicolumn{2}{|l|}{ Univariate } & \multicolumn{2}{|l|}{ Multivariate* } \\
\hline & Coefficients (SE) & $P$-value & Coefficients (SE) & $P$-value \\
\hline Waist circumference (cm) & $0.915(0.706)$ & 0.195 & $0.283(0.354)$ & 0.425 \\
\hline BMI z-score & $0.653(0.270)$ & 0.016 & $0.923(0.276)$ & $<0.001$ \\
\hline Systolic blood pressure (mmHg) & $-0.716(0.724)$ & 0.324 & $-0.166(0.688)$ & 0.809 \\
\hline Diastolic blood pressure $(\mathrm{mmHg})$ & $-0.468(0.718)$ & 0.515 & $0.146(0.708)$ & 0.836 \\
\hline fasting plasma glucose (mg/dL) & $-0.001(0.503)$ & 0.998 & $-0.136(0.501)$ & 0.785 \\
\hline Glycated hemoglobin (\%) & $0.999(0.004)$ & $<0.001$ & $0.999(0.004)$ & $<0.001$ \\
\hline Triglyceride (mg/dL) & $0.078(0.037)$ & 0.037 & $0.076(0.035)$ & 0.031 \\
\hline $\mathrm{HDL}-\mathrm{C}(\mathrm{mg} / \mathrm{dL})$ & $0.016(0.015)$ & 0.283 & $0.014(0.015)$ & 0.344 \\
\hline $\operatorname{ALT}(I U / L)$ & $0.096(0.036)$ & 0.008 & $0.113(0.031)$ & $<0.001$ \\
\hline
\end{tabular}

Triglyceride, HDL-C, and ALT was log-transformed for the analysis.

HGl, hemoglobin glycation index; SE, standard error; BMI, body mass index; HDL-C, high-density lipoprotein cholesterol; ALT, alanine aminotransferase.

*Adjusted for BMl z-score and hemoglobin.

Table 4. Association between HGI and CMRF clustering, metabolic syndrome, and ALT elevation according to sex, age group, and BMI category

\begin{tabular}{|c|c|c|c|c|c|c|}
\hline \multirow{2}{*}{ Variable } & \multicolumn{2}{|c|}{ CMRF clustering } & \multicolumn{2}{|c|}{ Metabolic syndrome } & \multicolumn{2}{|c|}{ ALT elevation } \\
\hline & OR $(95 \% \mathrm{Cl})$ & $P$-value & OR $(95 \% \mathrm{Cl})$ & $P$-value & OR $(95 \% \mathrm{Cl})$ & $P$-value \\
\hline \multicolumn{7}{|l|}{ Sex } \\
\hline Boys & $0.79(0.42-1.51)$ & 0.476 & $0.88(0.16-4.89)$ & 0.886 & $1.42(0.60-3.32)$ & 0.424 \\
\hline Girls & $2.38(0.98-5.74)$ & 0.054 & $1.06(0.16-6.80)$ & 0.953 & $1.29(0.54-3.10)$ & 0.180 \\
\hline \multicolumn{7}{|l|}{ Age (yr) } \\
\hline $10-14$ & $1.18(0.57-2.44)$ & 0.650 & $1.34(0.22-8.05)$ & 0.751 & $1.04(0.47-2.30)$ & 0.913 \\
\hline $15-18$ & $1.47(0.66-3.29)$ & 0.349 & $0.80(0.15-4.26)$ & 0.797 & $1.56(0.65-3.76)$ & 0.323 \\
\hline \multicolumn{7}{|l|}{ BMI category } \\
\hline Normal & $0.91(0.40-2.03)$ & 0.812 & $1.36(0.03-72.3)$ & 0.880 & $0.90(0.39-2.08)$ & 0.804 \\
\hline Overweight and obese & $2.92(1.47-5.80)$ & 0.002 & $1.77(0.56-5.61)$ & 0.330 & $2.72(1.24-5.98)$ & 0.013 \\
\hline
\end{tabular}

$\mathrm{HGl}$, hemoglobin glycation index; CMRF, cardiometabolic risk factor; ALT, alanine aminotransferase; BMI, body mass index; OR, odds ratio; $\mathrm{Cl}$, confidence interval.

Adjusted for sex, age group, BMI category, and hemoglobin.

than their glucose values have been classified as high and low glycators, respectively. HGI is a quantification of the difference between measured $\mathrm{HbA} 1_{c}$ and predicted $\mathrm{HbA} 1_{c}$, which is thought to represent the difference in glycation of hemoglobin among people with the same FPG. In T1DM patients, the higher the HGI level, the more microvascular complications such as retinopathy and nephropathy have been observed. ${ }^{28)}$ Moreover, a correlation between glycation gap and micro- and macrovascular complications has been reported in patients with T2DM. ${ }^{29)}$ One recent study reported that the higher the HGI level was, the higher was the risk of atherosclerosis and coronary artery calcification, which is a cardiovascular disease risk, even in nondiabetic adults. ${ }^{19)}$ These data support the fact that nonenzymatic protein glycation is one of the key players in explaining micro- and macrovascular complications associated with hyperglycemia. To the best of the authors' knowledge, the present study is the first study to investigate the clinical relevance of HGI and association between HGI and CMRFs and ALT in the pediatric non-diabetic population by using nationally representative data.

MS is a combination of 3 out of 5 risk factors, such as abdo- minal obesity, elevated BP, high fasting glucose, high TG, and low HDL-C. A better understanding of the metabolic abnormalities in adolescence could lead to preventive interventions that could improve adolescents' health outcomes and contribute to a reduction in cardiovascular disease in adults. ${ }^{30,31)}$ In recent years, concerns have been raised about issues with difficulties in defining and applying MS to youth in clinical practice, therefore, it is important to individually evaluate and manage these cases with a focus to CMRF clustering. ${ }^{24)}$

In the present study, TG was associated with HGI. High TG levels were observed in the state with decreased insulin sensitivity, which was related to glucose metabolism in muscles. ${ }^{32,33)}$ HGI might be associated with the insulin resistance, which was an underlying mechanism of MS. ${ }^{24)}$ The relationship between HGI and MS was not significant, although HGI and CMRF clustering were significantly associated. This suggests that the duration of exposure to higher levels of glucose or variation of glucose levels were relatively short and small in early childhood and adolescent periods for the occurrence of metabolic derangements. It might the affect the numbers of CMRFs in the study participants. 
Overweight/obese subjects showed significant correlation between HGI and CMRF clustering, although HGI was not significantly different between groups by BMI category (normal weight -0.005 versus overweight/obese $0.018, P=0.052$ ). Overweight/obese youth with higher HGI might have the more active the intracellular protein glycation process than those with normal weight, which could make difference in association with CMRF clustering according to BMI category. Therefore, HGI might be an alternative marker for an increased cardiometabolic risk in the pediatric population.

NAFLD has become a significant cause of chronic liver disease in childhood. It is associated with obesity, which might be considered as hepatic manifestation of MS. ${ }^{34)}$ Although liver biopsy has been considered the gold standard for diagnosing NAFLD, its invasiveness frequently makes it difficult to perform. ${ }^{25)}$ Currently, ALT is used as a surrogate marker of NAFLD. In a recent study, a correlation was found between elevated ALT ( $>30$ IU/L for males and >19 IU/L for females) and MS and insulin resistance in Korean adolescents. ${ }^{26)}$ In adults, high HGI was associated with hepatic steatosis in nondiabetic population. ${ }^{20)}$ In the present study, ALT was associated with higher HGI values in overweight/obese group. Further study is required to elucidate the association between HGI and NAFLD in pediatric population.

The limitation of this study is that its design was crosssectional, making it difficult to understand the causal relationship. However, the present study is the first study to investigate the clinical relevance of HGI and to evaluate the association between HGI and CMRFs and ALT in the pediatric nondiabetic population by using nationally representative data.

In this study, HGI was associated with CMRFs, including BMI $z$-scores, obesity, total cholesterol, ALT, abdominal obesity, elevated TG levels, and CMRF clustering in a pediatric nondiabetic population. When stratified for sex, age group, and BMI category, overweight/obese subjects showed linear trends for the presence of CMRF clustering and ALT elevation with respect to increases in HGI. We, therefore, suggest that there is a possibility that HGI might be used as an alternative marker for cardiovascular diseases in a pediatric population. However, further longitudinal studies are warranted to investigate clinical implications of HGI in children and adolescents.

\section{Conflict of interest}

No potential conflict of interest relevant to this article was reported.

\section{References}

1. Ng M, Fleming T, Robinson M, Thomson B, Graetz N, Margono C, et al. Global, regional, and national prevalence of overweight and obesity in children and adults during 1980-2013: a systematic analysis for the Global Burden of Disease Study 2013. Lancet 2014;384:766-81.
2. Fazeli Farsani S, van der Aa MP, van der Vorst MM, Knibbe CA, de Boer A. Global trends in the incidence and prevalence of type 2 diabetes in children and adolescents: a systematic review and evaluation of methodological approaches. Diabetologia 2013;56:1471-88.

3. Nam HK, Kim HR, Rhie YJ, Lee KH. Trends in the prevalence of extreme obesity among Korean children and adolescents from 2001 to 2014. J Pediatr Endocrinol Metab 2017;30:517-23.

4. Lee JH, Kim YM, Kwak MJ, Kim SY, Kim HJ, Cheon CK, et al. Incidence trends and associated factors of diabetes mellitus in Korean children and adolescents: a retrospective cohort study in Busan and Gyeongnam. Ann Pediatr Endocrinol Metab 2015;20:206-12.

5. Styne DM, Arslanian SA, Connor EL, Farooqi IS, Murad $\mathrm{MH}$, Silverstein JH, et al. Pediatric obesity-assessment, treatment, and prevention: an endocrine society clinical practice guideline. J Clin Endocrinol Metab 2017;102:70957.

6. Zeitler P, Fu J, Tandon N, Nadeau K, Urakami T, Barrett T, et al. ISPAD clinical practice consensus guidelines 2014. Type 2 diabetes in the child and adolescent. Pediatr Diabetes 2014;15 Suppl 20:26-46.

7. Cameron FJ, Wherrett DK. Care of diabetes in children and adolescents: controversies, changes, and consensus. Lancet 2015;385:2096-106.

8. Seo JY, Kim JH.Validation of surrogate markers for metabolic syndrome and cardiometabolic risk factor clustering in children and adolescents: a nationwide population-based study. PLoS One 2017;12:e0186050.

9. Nightingale CM, Rudnicka AR, Owen CG, Newton SL, Bales JL, Donin AS, et al. Birthweight and risk markers for type 2 diabetes and cardiovascular disease in childhood: the Child Heart and Health Study in England (CHASE). Diabetologia 2015;58:474-84.

10. American Diabetes Association. 6. Glycemic targets: standards of medical care in diabetes-2018. Diabetes Care 2018;41(Suppl 1):S55-S64.

11. Koenig RJ, Peterson CM, Jones RL, Saudek C, Lehrman M, Cerami A. Correlation of glucose regulation and hemoglobin AIc in diabetes mellitus. N Engl J Med 1976;295:417-20.

12. Cavagnolli G, Pimentel AL, Freitas PA, Gross JL, Camargo JL. Factors affecting A1C in non-diabetic individuals: review and meta-analysis. Clin Chim Acta 2015;445:10714.

13. Rohlfing C, Wiedmeyer HM, Little R, Grotz VL, Tennill A, England J, et al. Biological variation of glycohemoglobin. Clin Chem 2002;48:1116-8.

14. Cohen RM, Snieder H, Lindsell CJ, Beyan H, Hawa MI, Blinko S, et al. Evidence for independent heritability of the glycation gap (glycosylation gap) fraction of HbAlc in nondiabetic twins. Diabetes Care 2006;29:1739-43.

15. Seo JY, Hwang SS, Kim JH, Lee YA, Lee SY, Shin CH, et al. Distribution of glycated haemoglobin and its determinants in Korean youth and young adults: a nationwide popula- 
tion-based study. Sci Rep 2018;8:1962.

16. Herman WH, Ma Y, Uwaifo G, Haffner S, Kahn SE, Horton ES, et al. Differences in A1C by race and ethnicity among patients with impaired glucose tolerance in the Diabetes Prevention Program. Diabetes Care 2007;30:2453-7.

17. Hempe JM, Gomez R, McCarter RJ Jr, Chalew SA. High and low hemoglobin glycation phenotypes in type 1 diabetes: a challenge for interpretation of glycemic control. J Diabetes Complications 2002;16:313-20.

18. Ahn CH, Min SH, Lee DH, Oh TJ, Kim KM, Moon JH, et al. Hemoglobin glycation index is associated with cardiovascular diseases in people with impaired glucose metabolism. J Clin Endocrinol Metab 2017;102:2905-13.

19. Marini MA, Fiorentino TV, Succurro E, Pedace E, Andreozzi F, Sciacqua A, et al. Association between hemoglobin glycation index with insulin resistance and carotid atherosclerosis in non-diabetic individuals. PLoS One 2017; 12:e0175547.

20. Fiorentino TV, Marini MA, Succurro E, Andreozzi F, Sciacqua A, Hribal ML, et al. Association between hemoglobin glycation index and hepatic steatosis in nondiabetic individuals. Diabetes Res Clin Pract 2017;134:5361.

21. Soros AA, Chalew SA, McCarter RJ, Shepard R, Hempe JM. Hemoglobin glycation index: a robust measure of hemoglobin Alc bias in pediatric type 1 diabetes patients. Pediatr Diabetes 2010;11:455-61.

22. Kim JH, Yun S, Hwang SS, Shim JO, Chae HW, Lee YJ, et al. The 2017 Korean National Growth Charts for children and adolescents: development, improvement, and prospects. Korean J Pediatr 2018;61:135-49.

23. Zimmet P, Alberti KG, Kaufman F, Tajima N, Silink M, Arslanian S, et al. The metabolic syndrome in children and adolescents - an IDF consensus report. Pediatr Diabetes 2007;8:299-306.

24. Magge SN, Goodman E, Armstrong SC; Committee on Nutrition; Section on Endocrinology; Section on Obesity. The metabolic syndrome in children and adolescents: shifting the focus to cardiometabolic risk factor clustering. Pediatrics 2017;140(2). pii: e20171603. https://doi.org/10. 1542/peds.2017-1603.
25. Vos MB, Abrams SH, Barlow SE, Caprio S, Daniels SR, Kohli $\mathrm{R}$, et al. NASPGHAN clinical practice guideline for the diagnosis and treatment of nonalcoholic fatty liver disease in children: recommendations from the Expert Committee on NAFLD (ECON) and the North American Society of Pediatric Gastroenterology, Hepatology and Nutrition (NASPGHAN). J Pediatr Gastroenterol Nutr 2017;64:31934.

26. Park HK, Hwang JS, Moon JS, Lee JA, Kim DH, Lim JS. Healthy range of serum alanine aminotransferase and its predictive power for cardiovascular risk in children and adolescents. J Pediatr Gastroenterol Nutr 2013;56:686-91.

27. Kang Y, Park S, Kim S, Koh H. Estimated prevalence of adolescents with nonalcoholic fatty liver disease in Korea. J Korean Med Sci 2018;33:e109.

28. McCarter RJ, Hempe JM, Gomez R, Chalew SA. Biological variation in $\mathrm{HbA} 1 \mathrm{c}$ predicts risk of retinopathy and nephropathy in type 1 diabetes. Diabetes Care 2004;27: 1259-64.

29. Hempe JM, Liu S, Myers L, McCarter RJ, Buse JB, Fonseca V. The hemoglobin glycation index identifies subpopulations with harms or benefits from intensive treatment in the ACCORD trial. Diabetes Care 2015;38:1067-74.

30. Johnson WD, Kroon JJ, Greenway FL, Bouchard C, Ryan D, Katzmarzyk PT. Prevalence of risk factors for metabolic syndrome in adolescents: National Health and Nutrition Examination Survey (NHANES), 2001-2006. Arch Pediatr Adolesc Med 2009; 163:371-7.

31. Morrison JA, Friedman LA, Wang P, Glueck CJ. Metabolic syndrome in childhood predicts adult metabolic syndrome and type 2 diabetes mellitus 25 to 30 years later. J Pediatr 2008;152:201-6.

32. Pan DA, Lillioja S, Kriketos AD, Milner MR, Baur LA, Bogardus C, et al. Skeletal muscle triglyceride levels are inversely related to insulin action. Diabetes 1997;46:983-8.

33. Kelley DE, Goodpaster BH. Skeletal muscle triglyceride. An aspect of regional adiposity and insulin resistance. Diabetes Care 2001;24:933-41.

34. Asrih M, Jornayvaz FR. Metabolic syndrome and nonalcoholic fatty liver disease: Is insulin resistance the link? Mol Cell Endocrinol 2015;418 Pt 1:55-65. 